\title{
Attitudes, Beliefs, and Practices Regarding Asthma Care Among Providers and Adult Asthmatics in Imperial County
}

\author{
Paula Kriner ${ }^{1}$, Yolanda Bernal $^{1}$, Amy Binggeli ${ }^{1}$, India Ornelas ${ }^{2}$ \\ ${ }^{1}$ Imperial County Public Health Department \\ ${ }^{2}$ California Office of Binational Border Health
}

\begin{abstract}
Resumen
Asthma is a major cause of morbidity in children and adults. Imperial County has reported among the highest asthma hospitalization rates in the state. Factors such as poverty, access to care, poor selfmanagement skills, and ethnocultural beliefs may influence asthma exacerbations. Provider and adult asthmatic attitudes, beliefs, and practices regarding asthma were examined using a mixed-methods approach: a survey to evaluate provider conformance with national guidelines, and focus groups targeting medical practitioners and adult asthmatics. Half of all providers who treat asthmatics completed a self-administered survey about asthma diagnosis; clinical monitoring of patients; treatment; patient education; and practice guidelines. Provider focus groups further explored survey results. Adult asthmatics participated in Spanishlanguage focus groups exploring cultural beliefs, attitudes, and practices.

El asma es la mayor causa de morbilidad entre niños y adultos. El Condado de Imperial ha reportado las tazas más altas de hospitalización a causa de asma en el estado. Factores como la pobreza, acceso a cuidado médico, falta de experiencia sobre como manejar la enfermedad, y creencias étnicas y culturales pueden tener una influencia en las exacerbaciones del asma. Las actitudes, creencias, y prácticas de proveedores de atención médica y adultos concerniente al asma fueron examinadas utilizando varios métodos: una encuesta con el fin de evaluar el nivel de conformidad de los proveedores según las pautas establecidas a nivel nacional, y grupos foco con médicos y adultos con asma. La mitad de los proveedores que proveen atención a asmáticos completaron una encuesta acerca del diagnosis de asma; el monitoreo clínico de los pacientes; administración de tratamiento; educación a los pacientes; y pautas establecidas para proveer atención a pacientes con asma. Los grupos foco con los proveedores exploraron aun más los resultados de las encuestas. Los adultos con asma participaron en grupos foco dirigidos en español para explorar más a fondo las creencias culturales, actitudes y prácticas.
\end{abstract}

(C) 2003 Californian Journal of Health Promotion. All rights reserved.

Keywords: asthma, Imperial County, hospitalization, providers

\section{Introduction}

Asthma is one of the most common chronic illnesses in the United States. The prevalence is increasing, with an estimated 100 million asthma patients worldwide, and in the United States alone, an estimated 14 to 15 million persons with asthma (National Asthma Education and Prevention Program, 1997). The increasing prevalence of this disease is associated with increased morbidity and mortality (Kemp, 1998). Although it is highly prevalent in the general population, asthma disproportionately affects individuals of lower socioeconomic status and of racial and ethnic minority groups (Pachter et al., 2002).

Asthma- related health- care expenditures continue to increase, with asthma-related costs including both direct expenses (i.e., hospital care, clinic visits, and drug therapy) and indirect costs such as time lost from work and daily activities (Kemp, 1998). Asthma hospitalization 
rates in Imperial County have increased dramatically over the past decade. In 19951997, Imperial County reported the highest childhood asthma hospitalization rate and the second highest asthma hospitalization rate for all age groups in California. In order to improve quality of life and decrease morbidity and mortality among asthmatics, asthma selfmanagement programs have become an integral part of asthma treatment. The goal of such programs is to strengthen the partnership between patients and health-care providers in controlling the condition (Caplin et al., 2001). Self-management has produced results that are promising, and the Expert Panel 2 Report recommends, "Teach asthma self-management, tailoring the approach to the needs of each patient" (National Asthma Education and Prevention Program, 1997). The report discusses the need for health-care providers and patients to jointly develop and attain treatment goals together. The opportunity to jointly develop and attain treatment goals can be very challenging and at times distressing if the patient and health-care provider see asthma attitudes, beliefs, and practices differently.

Factors such as poverty, poor self-management skills, and ethnocultural beliefs may influence asthma care, exacerbations, and hospitalization rates. Further, with asthmatic patients' attitudes, beliefs, and practices playing a pivotal role in understanding, defining, and responding to illness, formulating a diagnosis, and understanding the disease and its treatment, it is important to understand their beliefs and work within that context (Enarson et al., 1999). Individuals often combine both biomedical and alternative medical beliefs and practices in their approach to illness, and providers should be aware of community and cultural beliefs and practices in order to optimize health education and clinical management strategies (Pachter et al., 2002). If health-care providers are unaware of these practices and beliefs, treatment and management may be delayed or discontinued by the adult asthmatic.

Although the reasons for initiating asthma selfmanagement programs are numerous (Lahdensuo, 1999), it is not always an easy task for health-care providers. Giving asthmatic patients more responsibility and independence may be a cultural challenge for health-care staff and starting a new program can also mean additional staff workloads (Lahdensuo, 1999). Educating and motivating both health-care providers, teams and patients are crucial for successful self-management and can be very challenging when health-care providers are unaware of guidelines, lack appropriate resources, equipment, and time, and experience language barriers.

Located in California's southeastern corner, Imperial County (estimated population 150,800) is Southern California's only designated rural county. The county shares a border with a major metropolis, Mexicali, Mexico. Imperial County has the highest percentage of Latino residents $(72 \%)$ of all California counties. Twenty-nine percent of Imperial County residents live at or below the Federal Poverty Level, compared to $16 \%$ of California's overall population.

In a collaborative effort, the Imperial County Public Health Department, El Centro Regional Medical Center, Clinicas de Salud del Pueblo, Inc., and Valley Family Care Center have begun collecting quantitative and qualitative data to explore asthma attitudes, beliefs, and practices in Imperial County, both among providers and adult asthmatics. The aim of this mixedmethods study is to explore provider attitudes, beliefs, and practices of asthma care, as well as those of Latino adult asthmatics regarding asthma causes, symptoms, and treatments. In doing so, it is hoped that asthma selfmanagement and quality of life will be improved.

\section{Method}

\section{Experiment 1}

Provider and adult asthmatic perceptions regarding asthma care attitudes, beliefs, and practices were examined using a mixed-methods approach that included a survey; two focus groups targeting medical practitioners who provide asthma care; and three focus groups targeting adult asthmatics. 


\section{Survey Participants}

Forty two out of 80 eligible health-care providers who treat patients with asthma in Imperial County, California, completed surveys. Public Health Department staff contacted all providers to determine if they treated patients with asthma. Providers were considered ineligible if they had retired from practice or if they estimated that less than $1 \%$ of their patients had asthma. Most of the 42 respondents are family or general practice physicians $(\mathrm{N}=17$, $40.5 \%) ; 26 \%(\mathrm{~N}=11)$ are pediatricians; $9.5 \%$ $(\mathrm{N}=4)$ are internists; $7 \%(\mathrm{~N}=3)$ are nurse practitioners; $7 \%(\mathrm{~N}=3)$ are emergency medicine doctors; and 9.5\% ( $\mathrm{N}=4)$ represent various other specialties (including cardiology, hematology/ oncology, and surgery). The majority of respondents $(\mathrm{N}=25,59.5 \%)$ obtained their medical education in the United States. Twelve percent $(\mathrm{N}=5)$ received their medical education in Mexico; $7.1 \%(\mathrm{~N}=3)$ in Pakistan; and $4.8 \%$ $(\mathrm{N}=2)$ in the Philippines. Another $11.9 \%(\mathrm{~N}=5)$ were educated abroad in a variety of countries. Two $(4.8 \%)$ did not respond to the question. One-third of the respondents $(\mathrm{N}=14)$ practice at Clinicas de Salud del Pueblo, Inc.; one-third $(\mathrm{N}=14)$ work at one of the Valley Family Care Center clinics; $21.4 \%(\mathrm{~N}=9)$ are affiliated with Pioneers Memorial Hospital; and 4.8\% ( $\mathrm{N}=2)$ work at El Centro Regional Medical Center. Another three respondents (7\%) work for the Imperial County Public Health Department.

\section{Materials}

A two-page, self-administered survey was created to examine the asthma care practices of area providers and to determine whether the providers use the National Asthma Education and Prevention Program (NAEPP) guidelines. The national guidelines were established to provide a general approach to diagnosing and managing asthma based on current science with the goal of improving asthma care and thereby reducing adverse outcomes and hospitalizations (National Asthma Education and Prevention Program).

\section{Design and Procedure}

The survey instrument was based in part on a previous asthma survey of Chicago-area physicians (Grant, Moy, Turner-Roan, Daugherty, \& Weiss, 1999) and another similar survey (Finkelstein et al., 2000). The survey instrument was pilot-tested among a small sample of local providers before being distributed in late 2001 at medical staff meetings at El Centro Regional Medical Center and Pioneers Memorial Healthcare District and to providers at Valley Family Care Center and Clinicas de Salud del Pueblo, Inc., in Imperial County. The survey includes questions regarding asthma diagnosis; clinical monitoring of asthma patients; pharmacologic and non-pharmacologic asthma treatment; patient education; and use of asthma practice guidelines.

\section{Results}

The vast majority of survey respondents $(\mathrm{N}=35$, $83.3 \%$ ) estimated that $1 \%$ to $25 \%$ of their patients had asthma in the past year. Nearly $12 \%$ $(\mathrm{N}=5)$ reported that an estimated $26 \%$ to $50 \%$ of their patients had asthma in the past year. One $(2.4 \%)$ estimated that $51 \%$ to $75 \%$ of patients had asthma, and one $(2.4 \%)$ did not answer the question. Sixty-four percent (27) of respondents care for patients aged $0-5 ; 78.6 \%$ (33) treat patients aged $6-17 ; 73.8 \%(\mathrm{~N}=31)$ care for patients aged 18-64; and 59.5\% ( $=25)$ treat patients aged 65 and older.

Nearly all respondents $(\mathrm{N}=41,97.6 \%)$ reported giving new patients a physical exam as part of the initial evaluation to diagnose asthma cases (moderate to severe), and $88.1 \% \quad(\mathrm{~N}=37)$ reported obtaining an asthma-related history (Figure 1). The majority $(\mathrm{N}=26$ or $61.9 \%)$ reported doing a trial of beta-agonists. Spirometry and peak flow measurement were the most widely used diagnostic tests for initial evaluation ( $\mathrm{N}=22$ or $52.4 \%$ for each procedure). Chest radiograph was also commonly reported $(\mathrm{N}=18,42.9 \%)$. A trial of daily peak expiratory flow rate (PEFR) monitoring was used less frequently $(\mathrm{N}=14,33.3 \%)$. Sinus radiographs $(\mathrm{N}=6, \quad 14.3 \%)$, skin or radioallergosorbent testing ( $\mathrm{N}=4,9.5 \%)$, and sputum exam and stain for eosinophilia $(\mathrm{N}=1,2.4 \%)$ were used infrequently. 


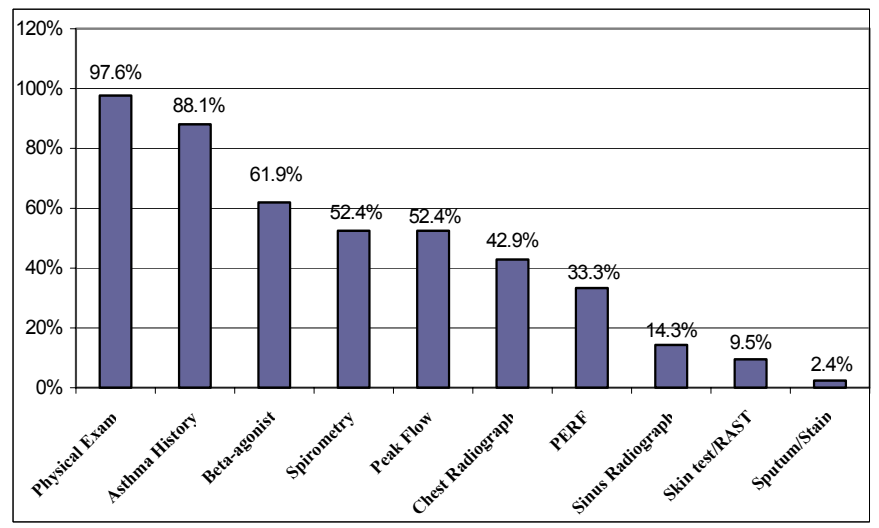

Figure 1

Approach to Initial Evaluation Reported by Imperial County Providers Who Treat Asthma Patients

Nearly all providers $(\mathrm{N}=39,92.9 \%)$ reported routinely scheduling follow-up visits for asthma patients (Figure 2). The respondents reported that during follow-up office visits they most often monitored the following: symptoms of wheeze and cough $(\mathrm{N}=38,90.5 \%)$; beta2-agonist use $(\mathrm{N}=33,78.6 \%)$; loss of work/school days due to asthma $(\mathrm{N}=32,76.2 \%)$; frequency of disturbed sleep due to asthma symptoms $(\mathrm{N}=29$, $69 \%)$; activity levels $(\mathrm{N}=28,66.7 \%)$; and direct observation of inhaler technique $(\mathrm{N}=22,52.4 \%)$. Office peak flow measurement and review of peak flow diary were less frequently monitored at $47.6 \% \quad(\mathrm{~N}=20)$ and $42.9 \% \quad(\mathrm{~N}=18)$, respectively. Only $21.4 \% \quad(\mathrm{~N}=9) \quad$ reported routinely using spirometry.

Most respondents did not have direct access to spirometry; only $38.1 \%(\mathrm{~N}=16)$ reported having a spirometer in their office (Figure 3). Thirtyeight percent $(\mathrm{N}=16)$ reported that they referred patients to a specialist for spirometry; three of those providers also responded that there was a spirometer in their office. Another 26.2\% $(\mathrm{N}=11)$ of the providers referred patients to spirometry offsite at another clinic or hospital; four of those providers also responded that they made referrals to specialists. "No access" to spirometry was reported rarely $(\mathrm{N}=4,9.5 \%)$.

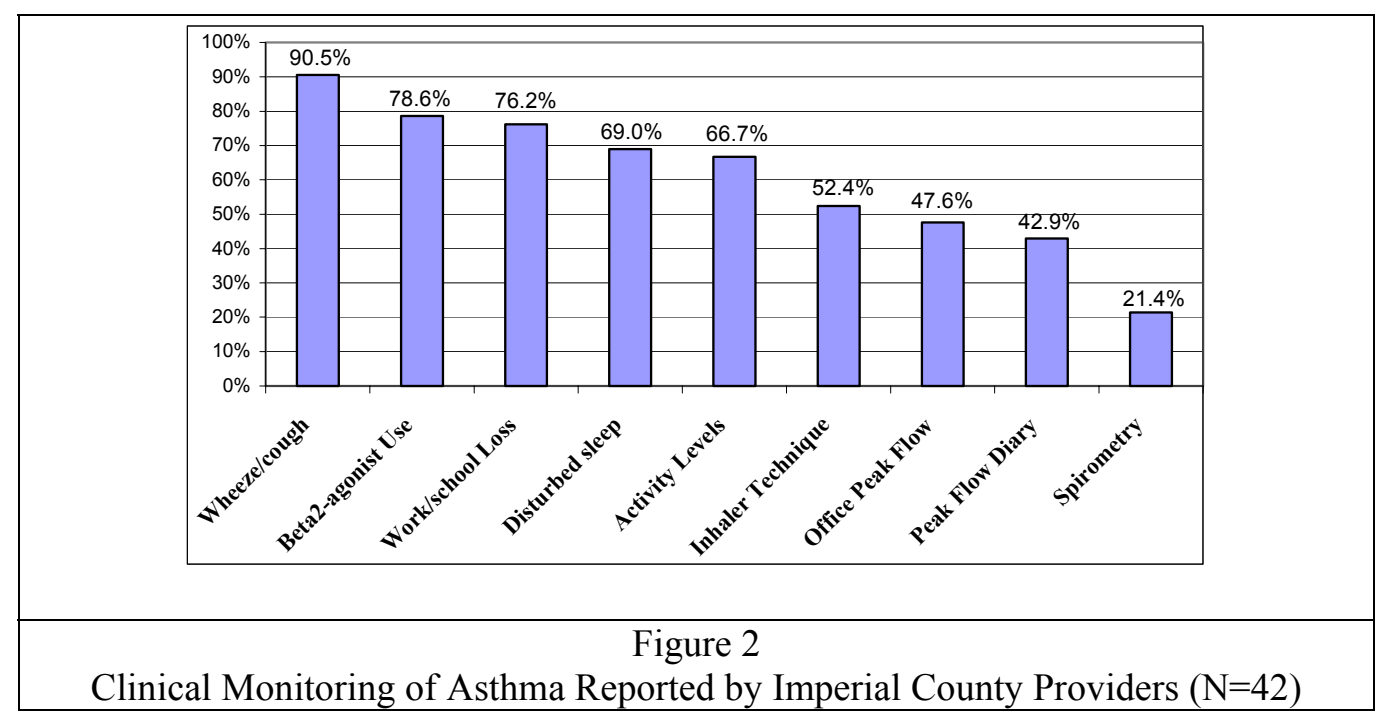




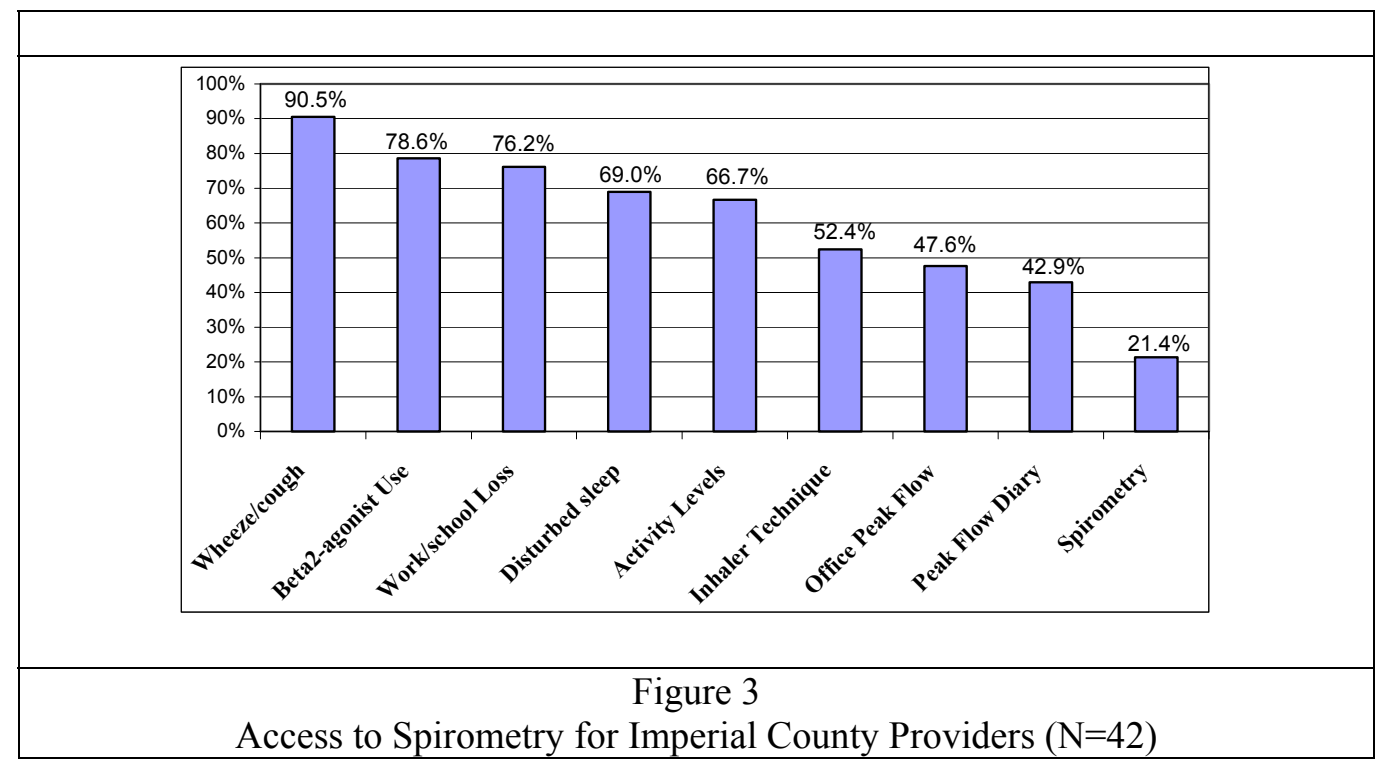

Most providers reported developing written treatment plans for at least some patients with moderate or severe persistent asthma (Figure 4). Forty-three percent $(\mathrm{N}=18)$ of respondents reported developing written plans for $1 \%-25 \%$ of patients with moderate or severe persistent asthma; 7.1\% ( $\mathrm{N}=3)$ developed plans for $26 \%$ $50 \%$ of those patients; and $14.3 \% \quad(\mathrm{~N}=6)$ provided written plans for $76 \%-100 \%$ of patients with moderate or severe persistent symptoms. Another 23.8\% ( $=10)$ did not provide patients with written plans. Half $(\mathrm{N}=21)$ of the providers reported that they often used peak flow or pulmonary function tests (PFT) for acutely symptomatic patients, while $16.7 \% \quad(\mathrm{~N}=7)$ reported sometimes using those tests and $21.4 \%$ (9) rarely used them. Two $(4.8 \%)$ never used either peak flow or PFT for symptomatic patients, and one $(2.4 \%)$ reported that peak flow or PFT were not available. Two $(4.8 \%)$ did not respond to the question.

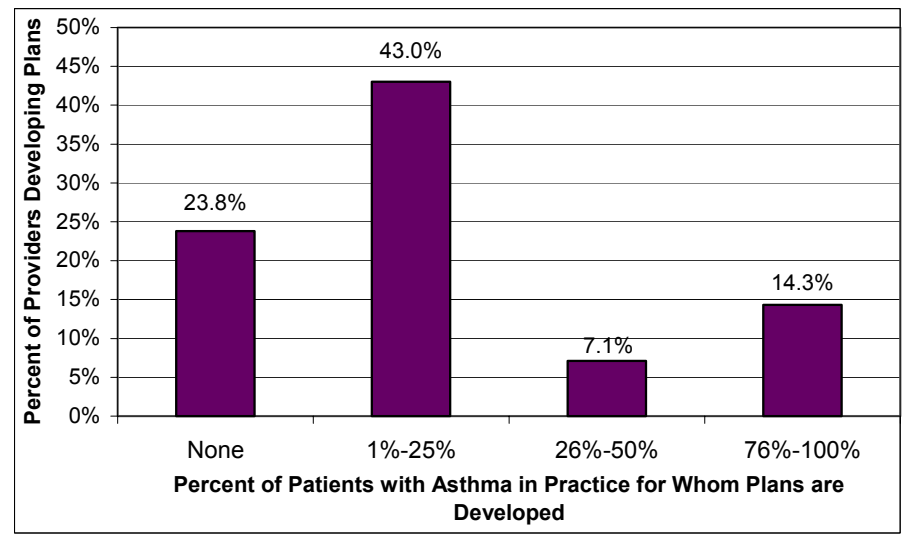

Figure 4

Written Treatment Plans Routinely Developed for Patients with Moderate or Severe Asthma $(\mathrm{N}=42)$ 
Only $28.6 \%(\mathrm{~N}=12)$ of the respondents reported that they often used peak flow or PFT for asymptomatic patients, while $19 \%(\mathrm{~N}=8)$ sometimes used them and $31 \%(\mathrm{~N}=13)$ rarely used them for patients without symptoms. Another $14.3 \%(\mathrm{~N}=6)$ never used peak flow or PFT for asymptomatic patients. One (2.4\%) indicated that those tests were not available, and two $(4.8 \%)$ did not respond to the question. Nearly all respondents $(\mathrm{N}=39,92.9 \%)$ reported prescribing some sort of metered dose inhaler (MDI) to some of their patients with asthma. Nearly $41 \%(\mathrm{~N}=17)$ of providers prescribed some sort of MDI to $76 \%-100 \%$ of their patients with asthma (see Table 1). Of those providers who prescribed some type of MDI to asthma patients, nearly all $(\mathrm{N}=38,90.5 \%)$ also prescribed a spacer device to some of those patients. Similarly, nearly all providers $(\mathrm{N}=39$, $92.9 \%$ ) reported prescribing a corticosteroid inhaler to some of their patients with moderate or severe asthma. Almost half $(\mathrm{N}=20,47.6 \%)$ prescribed them to $76 \%-100 \%$ of those patients. Most providers also prescribed a spacer device to some but not all of those patients.

The providers were asked about the likelihood of prescribing oral beta-agonists for patients with moderate persistent asthma. Thirty-eight percent $(\mathrm{N}=16)$ of respondents reported that they often prescribed oral beta-agonists for patients with moderate persistent asthma, while $11.9 \%$ sometimes prescribed that type of medication. The greatest number $(\mathrm{N}=17,40.5 \%)$ rarely prescribed oral beta-agonists for patients with moderate persistent asthma. One respondent $(2.4 \%)$ never prescribed oral beta-agonists for patients with asthma.

\begin{tabular}{|l|c|c|c|c|c|}
\hline & $\begin{array}{c}\mathbf{1 - 2 5 \%} \\
(\mathbf{N})\end{array}$ & $\begin{array}{c}\mathbf{2 6 - 5 0 \%} \\
(\mathbf{N})\end{array}$ & $\begin{array}{c}\mathbf{5 1 - 7 5 \%} \\
(\mathbf{N})\end{array}$ & $\begin{array}{c}\mathbf{7 6 - 1 0 0 \%} \\
(\mathbf{N})\end{array}$ & None \\
\hline Percent patients in past year prescribed MDI & $19 \%(8)$ & $7.1 \%(3)$ & $26.2 \%(11)$ & $40.5 \%(7)$ & $2.4 \% 1)$ \\
\hline$\Rightarrow \%$ of those patients with spacer device & $47.6 \%(20)$ & $21.4 \%(9)$ & $11.9 \%(5)$ & $9.5 \%(4)$ & $4.8 \% 2)$ \\
\hline $\begin{array}{l}\text { Percent patients in past year prescribed } \\
\text { corticosteriod inhaler }\end{array}$ & $23.8 \%(10)$ & $9.5 \%(4)$ & $11.9 \%(5)$ & $47.6 \% 20)$ & $2.4 \% 1)$ \\
\hline$\Rightarrow \%$ of those patients with spacer device & $33.3 \%(14)$ & $19 \%(8)$ & $23.8 \%(10)$ & $9.5 \%(4)$ & $9.5 \% 4)$ \\
\hline
\end{tabular}

Table 1

Management of Asthma: Provider Prescription of Inhalers

The majority of providers $(\mathrm{N}=35,83.3 \%)$ reported incorporating some type of patient education, while three $(7.1 \%)$ did not provide education of any kind. Most respondents $(\mathrm{N}=27, \quad 64.3 \%)$ offered informal asthma education delivered by a nurse or physician with or without written materials. Nearly $36 \%$ $(\mathrm{N}=15)$ of respondents provided written materials from a variety of sources ranging from pamphlets, brochures supplied by pharmaceutical companies, WEB-based information from EDNET, and handwritten instructions. Another 9.5\% (N=4) reported that they referred patients to formal education programs.

Only one-third $(\mathrm{N}=14)$ of survey respondents reported often using the National Asthma Education and Prevention Program (NAEPP) guidelines for the diagnosis and treatment of asthma (Figure 5). Another 23.8\% ( $=10)$ of respondents reported rarely using the guidelines, while $19 \% \quad(\mathrm{~N}=8)$ sometimes used the guidelines, and $9.5 \%$ (4) never used the guidelines. Another 9.5\% ( $\mathrm{N}=4)$ reported that the guidelines were not available. Two $(4.8 \%)$ did not respond to the question. 


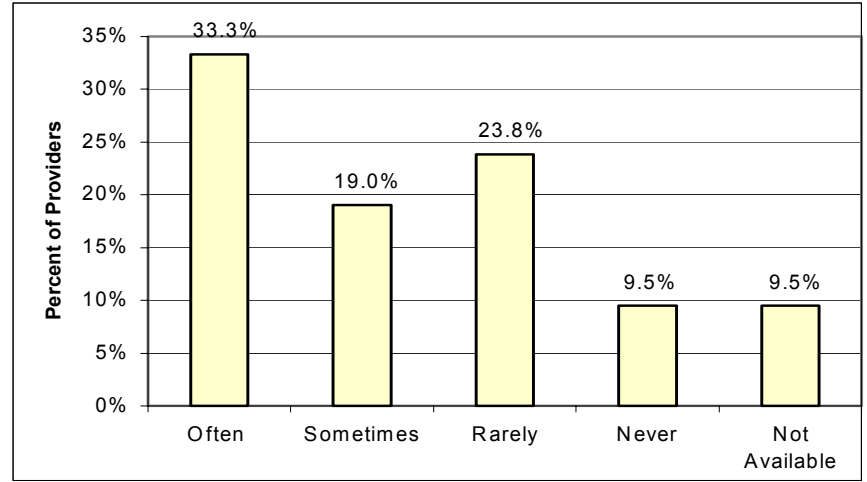

Figure 5

Providers' Self-Reported Use of NAEPP Guidelines $(\mathrm{n}=42)$

\section{Discussion}

The results of Experiment 1 indicate that most providers who treat asthma patients in Imperial County are aware of the NAEPP guidelines for recommendations for asthma treatment, but relatively few use those guidelines routinely. While Imperial County providers have incorporated several aspects of the guidelines into clinical practice, other standards have not been adopted. Areas where there is a difference between the guidelines' recommendations and provider practice in Imperial County include the use of written care plans and several key aspects of asthma care.

The use of written treatment plans is a key part of patient education and their use has been associated with decreased illness. The survey results indicate that many providers do not commonly provide all patients written treatment plans.

The guidelines recommend the use of peak expiratory flow rate (PERF) monitoring as an objective assessment of airway obstruction. The survey queried several aspects of peak flow use. Only one-third of respondents reported PERF monitoring for the initial evaluation of symptomatic patients and less than half of the respondents reported peak flow monitoring for the evaluation of patients with asthma during follow-up visits.

The guidelines recommend spirometry as a diagnostic test for all patients at initial presentation, but this does not appear to be the common practice of area providers. The majority of providers did not report having a spirometer in their office. The survey data on spirometry highlights an important area for intervention.

In the area of pharmacotherapy, the guidelines recommend anti-inflammatory therapy for all patients with persistent asthma. However, Imperial County providers are not prescribing inhaled anti-inflammatory medication for all patients with moderate or severe asthma.

Patient education is another vital part of asthma care. The NAEPP guidelines define key components and essential messages that should be delivered in office-based education. The guidelines suggest that in addition to education delivered by the clinician, all patients may benefit from formal asthma education programs taught by asthma educators. The survey results showed that formal education programs are rarely used. 


\section{Method}

\section{Experiment 2}

\section{Participants}

Health-care providers were recruited from a variety of medical practice sites throughout Imperial County to participate in focus group interviews to further examine asthma care practices and to determine providers' attitudes toward the NAEPP guidelines. A total of 11 providers were recruited: six men and five women. Seven providers - five physicians, a physician assistant, and a nurse practitioner from central and southern Imperial County participated in a focus group conducted in March 2002 in El Centro. Four pediatricians from the northern part of the county took part in a second focus group conducted in April 2002 in Brawley.

\section{Material}

A focus group guide was designed based on the results of the provider survey to standardize the questions asked of each group. The focus group discussion included questions regarding providers' use of the national guidelines for initial and follow-up visits; the classification system for severity of illness; use of patient diaries and written action plans; and use of written materials or videos for patient education. Providers also were asked about who they believe would be best to provide patient education, the type of instructional materials that should be used, the best setting for such education, and the utility or usefulness of tool kits for asthma patients.

\section{Design and Procedure}

The focus group interviews lasted approximately 1.5 hours. The focus groups interviews were tape-recorded. Focus group data were transcribed and content analyzed for emerging themes using grounded theory and axial coding methods.

\section{Results}

Themes emerged around provider perceptions that asthma was one of the most common and serious health problems that they see in their medical practices, barriers to patients' care, and recommendations to improve care. Barriers to patient care included lack of patient knowledge to appropriately manage their asthma, patient cultural beliefs, physicians' lack of time and appropriate equipment to diagnose and manage patients with asthma, and limited time and options for patient education.

Themes also emerged around provider recommendations for improving patient-centered asthma care including the importance of patient education; development of an asthma clinic; periodic medication review and follow-up with patients; various skills development and patient education strategies to meet the spectrum of patient needs; and providers' recommendations that patient education routes be flexible and that multiple teaching methods be used for patient education to ensure effectiveness.

Patients' failure to adhere to treatment regimens and self-medication are especially difficult problems for area providers. Imperial County's location next to the U.S.-Mexico border provides easy access for patients to obtain medications without a prescription in nearby Mexicali, Mexico. Providers noted patients' lack of knowledge in using asthma medications, both prescribed drugs and medicine obtained on their own in Mexico. Providers also mentioned patients' misconceptions about asthma drugs, such as the belief that using a nebulizer will prevent asthma attacks from ever occurring. One provider expressed concern about patients who use anti-inflammatory medication on its own, rather than in conjunction with a bronchodilator.

In one focus group, providers noted that Latino patients do not want to be diagnosed with asthma. "They don't like to hear the word 'asthma," one physician said. "They think that it entails [a] chronic, life-threatening illness." Providers believe cultural factors also influence patients' use of medications. "We talk about inhalers... they think the child is going to be addicted to it or they don't want to use it sometimes," one provider said. Some patients or parents of patients do not support using prescribed medications. They believe instead that if the patient does not take the medication that they will outgrow their asthma on their own. 
Patients' low literacy levels in both English and Spanish present a major barrier to the use of patient diaries or written treatment plans. One provider reported a successful solution to the problem: Nurses give oral instructions to patients along with asthma-care packets. "They teach the patient. They teach the parents. And then they (patients or parents) have to teach it back," the provider said. "That works out pretty good that way. But it takes a lot of time." Other providers who do incorporate patient diaries noted that they have had limited success with patients using diaries to monitor their asthma. Providers in both focus groups indicated that they believe patient diaries and action plans are useful.

Providers cited a lack of time to spend with patients to follow the guideline recommendations for the initial visit. "I have been in private practice before and I know that it was very busy and I couldn't have spent all the time that I spend with patients now," one physician said. Some providers reported that they do not use a spirometer for the initial assessment because they do not have one in their office or they depend on an allergy specialist to do the test.

Another significant barrier for patients in managing asthma is that they do not have access to peak flow meters. Medi-Cal, the state health insurance plan for low-income persons, does not pay for them and they are too costly (about \$25) for patients to purchase on their own.

Providers noted the importance of regularly reviewing patients' use of medications, as well as observing their use of inhalers or peak flow meters, to ensure that they are using them properly. Providers mentioned long-term patients who had never learned to use their medication appropriately. One patient who had been using an inhaler for 14 years told his physician that it did not work well. After the physician took the time to demonstrate how to use the inhaler properly, the patient told him, "Gosh, I never knew it could work this well."

Focus group participants also noted the value of ongoing education and a multi-faceted approach to educating patients. Some providers indicated that patients often do not read written materials, not because they are illiterate but because the pamphlets and other written information are too technical. Several providers stated that they provide only very basic information to patients. One physician uses pictures of a normal lung and an asthmatic lung to help patients understand how to use an inhaler. One provider carries an inhaler and demonstrates how to use it, while yet another physician tells patients basic information about triggers for asthma and the medicine they need to take, instead of relying on written materials.

Providers suggested that either a nurse specializing in asthma care, a health educator, or a team approach, such as the type that could be provided by an asthma-care clinic, would be the best ways to educate patients. "I think like any other chronic condition, it's just training and retraining and. . . . reinforcing it, basically," said one physician. Providers stressed that patient education routes need to be flexible. One provider suggested creating messages for the public that could be aired on radio or television to "demystify and de-stigmatize childhood asthma."

\section{Discussion}

Two exploratory focus groups conducted with area health-care providers offered insight into some of the barriers that prevent them from following the National Asthma Education and Prevention Program (NAEPP) guidelines. Most of the focus group participants indicated that asthma is one of the most common and serious health problems they encounter in their medical practices. In general, physicians reported that they do not have time to spend with patients to educate them about proper use of medication, peak flow meters, inhalers, and other tools to improve asthma management. Several providers noted that they do not have spirometers and other equipment in their offices to diagnose or help instruct patients in the management of their asthma. Providers also reported cultural, language, and literacy barriers that hinder patients' understanding of asthma care and management of their illness, as well as financial barriers that keep patients from acquiring 
equipment not covered by health insurance plans for low-income persons. A few providers noted patients' reluctance to use prescribed medications, as well as problems with patients who self-medicate.

Despite those limitations, providers recognize the importance of regularly reviewing medication regimens and proper techniques for using inhalers and peak flow meters, as well as overall patient education. There was general support for a coordinated team approach, such as an asthma-care clinic, for patient education.

\section{Method}

\section{Experiment 3}

\section{Participants}

Three focus group interviews were conducted in July 2002 with a total of seven people to explore cultural beliefs, attitudes, and practices among Spanish-speaking adult asthmatics. Participants were recruited by promotoras, who are community-identified leaders who provide culturally appropriate health education and information. All participants were women who ranged in age from 30 to 65 and had been diagnosed with asthma by a physician.

\section{Material}

A focus group guide was designed based on information provider by medical practitioners who participated in the provider focus groups to standardize the questions asked of each adult asthmatic group. The focus group discussion included questions regarding cultural beliefs related to asthma diagnosis, treatment, and management, and factors contributing to those cultural beliefs; possible strategies that could be used to enhance asthma diagnosis, treatment, and management compliance; and ideas for the development of an asthma "toolkit" for adult asthmatics.

\section{Design and Procedure}

The focus group interviews lasted approximately 2 hours. The focus group interviews were conducted in two different locations in Calexico and one in El Centro. The focus groups interviews were tape-recorded. Focus group data were transcribed, translated from Spanish to English by the focus group moderator. The content was analyzed for emerging themes using grounded theory and axial coding methods.

\section{Results}

Themes emerged around the role health-care providers play in diagnosing and treating adult asthmatics, the belief in home remedies being important in controlling asthma attacks, and beliefs about what causes asthma.

A major theme, which emerged throughout the focus group interviews, was the importance of being diagnosed with asthma by a provider. Diagnosis not only occurred in the provider's office as a result of the adult experiencing a prolonged dry cough, wheezing, and inability to breath, but also in the hospital. When asked how important it is to be diagnosed by a doctor, one participant expressed her feeling in this way, " It is very important. If not, how will you know you have asthma? The doctor showed me how to control my asthma and how to use inhalers..." Beliefs and practices about asthma control and management can play an integral role in how an asthmatic takes care of their condition. Ethnocultural beliefs in a community can have a greater influence on asthma self-management and control than a health-care provider's recommendations. A second focus group theme that emerged was that of home remedies and their role in controlling asthma attacks. Respondents identified a variety of home remedies that are seen as effective asthmacontrolling substances. The respondents were clear in their distinction between controlling and curing asthma. Cultural beliefs and home remedies that were identified as effective controllers included hot black coffee, "teas," and ingesting turtle oil before breakfast.

A third theme that emerged from the focus group interviews revolved around what the respondents believed to cause asthma. Respondents were well informed when it came to discussing and defining causes of asthma. Some of the causes included allergies, animals, pollen, detergent, perfumes, cigarette smoke, and chemicals. It is interesting to note, however, that although animals were identified as causing asthma, in one of the focus group interviews the Chihuahua dog was seen as an asthma "cure" for children. "....Chihuahua dogs are good for 
children, to cure their asthma.... They have to sleep with a Chihuahua dog so they [the dog] can absorb our illness... You supposedly sleep with the dog and while you breath the doggie gets all the bad inside of you."

\section{Discussion}

Three exploratory focus groups conducted with local adult asthmatics provided insight into some of our communities' cultural attitudes, beliefs, and practices around the topic of asthma diagnosis, management, and care. The response to asthma diagnosis being completed by a physician is an important and interesting finding, especially given that providers may sense reluctance by adults to be physician-diagnosed. Overall, adult asthmatics were well informed about asthma causation and triggers. But there appears to be a disconnect between animals being a cause of asthma and the curative properties of the Chihuahua dog for children with asthma.

\section{Conclusion}

One of the major findings of this mixed-methods study is the need for more patient education, information, and one-on-one training assistance for basic asthma care, as well as the dearth of patient education options available to providers and patients. In addition to patient education, the provider survey highlighted other opportunities for improvement among providers that include the use of written treatment action plans, routine follow-up care, and antiinflammatory medication.

Patient education is a vital part of asthma care. The NAEPP guidelines define key components and essential messages that should be delivered in office-based education. The guidelines suggest that in addition to education delivered by the clinician, all patients may benefit from formal asthma education programs taught by asthma educators. The survey results show that formal education programs are rarely used, in large part because they do not exist outside the private practice setting.

Provider focus group themes emerged regarding barriers to patient care, including sufficient patient knowledge to appropriately manage their asthma; patient cultural beliefs; lack of equipment for diagnosis; and limited patient education. Recommendations for improving asthma care in this region include development of an asthma clinic; periodic medication review and follow-up with patients; and various skills development and patient education strategies. The idea of using promotoras was introduced in provider focus groups as an option for patient education for health-care providers who do not have the time to provide such education in their practice. Promotoras are community-identified leaders who provide culturally appropriate health education and information, help ensure that services are obtained, and offer social support to area residents in need. Providers indicated that they would be receptive to the idea of using promotoras for outreach, education, and training in proper medication usage.

Adult asthmatic focus group themes emerged around ethnocultural beliefs regarding asthma triggers and treatment, but participants also identified and were very informed about proven asthma causation and triggers. Health-care providers were clearly identified as being important in an asthma diagnosis, which appears to contradict the perspective of the providers regarding adult asthmatics beliefs.

Focus group interview findings indicate that numerous barriers to patient asthma diagnosis and self-management exist. Themes emerging from this mixed-methods exploratory study may be useful in refining local asthma management programs, improving provider standard of care, and enhancing patient education. Findings also may have implications for Mexican providers because of patient population similarities in economic status, ethnicity, cultural beliefs, and other risk factors.

Our study shows that individuals in this predominantly Latino population are aware of and believe in the biomedical model for asthma. They combine this knowledge and practice with their own traditional beliefs and ethnocultural practices. Similarly, community surveys conducted by Pachter et al. among different Latino cultural groups suggest that educational 
interventions that reinforce the biomedical model and combine it whenever possible with these traditional, ethnocultural beliefs and practices would likely be more effective than interventions that assume that there are two conflicting belief systems that are mutually exclusive.

Poverty, lack of health insurance, and limited understanding about asthma are likely important factors in the high rate of hospitalizations for asthma exacerbations in Imperial County. Our study shows that asthmatics' fear of being diagnosed with the disease and failure to recognize asthma as a chronic disease, but instead treat it as an episodic illness, may also contribute to the problem.

The findings of the our provider survey, provider focus groups, and adult asthmatic focus groups were used as the basis of a patient education program using promotoras now being piloted.

Finally, some limitations of our investigation should be noted. Only half of all physicians who provide care to asthma patients in Imperial County completed the provider survey. We do not know if those who did not participate were not available on the days the surveys were distributed at staff meetings or if they were unwilling to participate. We do not know if their lack of participation was related in any way to their knowledge of or ability to appropriately diagnose and treatment asthma patients.

In recruiting providers for the focus group, we selected a purposive sample of physicians to participate based on their availability and interest in participating, rather than using a random sample of providers. Providers who agreed to participate may have been motivated by a large number of patients with asthma seen in their practice and so may not have been representative of the general physician population.

And lastly, we used a convenience sample of adult asthmatics to participate in the focus groups. All participants were women; we acknowledge that this, along with the limited number of participants in the interviews, may limit our ability to generalize our findings among the overall population of adult asthmatics in Imperial County.

\section{References}

Buseh, A. G., Glass, L. K., \& McElmurry, B. J. (2002). Cultural and gender issues related to hiv/aids prevention in rural Swaziland: A focus group analysis. Health Care for Women International, 23, 173-184

Caplin, D. L., \& Creer, T. L. (2001). A self-management program for adult asthma. III. Maintenance and relapse of skills. Journal of Asthma, 38, 343-356.

Enarson, D.A. \& Ait-Khaled, N. (1999). Cultural barriers to asthma management. Pediatric Pulmonology, 28, 297-300.

Finkelstein, J. A., Lozano, P., Shulruff, R., Inui, T. S., Soumerai, S. B., Ng, M., \& Weiss, K. B. (2000). Self-reported physician practices for children with asthma: Are national guidelines followed? Pediatrics, 106, 886-896.

Flores, G., Fuentes-Afflick, E., Barbot, O., Carter-Pokras, O., Claudio, L., Lara, M., McLaurin, J. A., et al. (2002). The health of latino children: Urgent priorities, unanswered questions, and a research agenda. Journal of the American Medical Association, 288, 82-90.

Grant, E. N., Moy, J. N., Li, T. V., Turner-Roan, K., Daugherty, S. R., \& Weiss, K. B. (1999). Asthma care practices, perceptions and beliefs of Chicago-area primary care physicians. Chest, 116, 145S-154S.

Harris, G. S., Shearer, A. G. (2001). Beliefs that support the behavior of people with asthma: a qualitative investigation. Journal of Asthma, 38, 427-434.

Kemp, J. P. (1998). Comprehensive asthma management: Guidelines for clinicians. Journal of Asthma, $35,601-620$. 
Lahdensuo, A. (1999). Guided self management of asthma - how to do it. British Medical Journal, 319, 759-760.

National Asthma Education and Prevention Program. (1997). Expert panel report 2: Guidelines for the diagnosis and management of asthma (Publ. No. 97-4051). Bethesda, MD: National Institutes of Health.

Pachter, L. M., Weller, S.C., Baer, R.D., Garcia de Alba Garcia, J. E., Trotter, R. T., Glazer, M. et al. (2002). Variation in asthma beliefs and practices among mainland Puerto Ricans, MexicanAmericans, Mexicans, and Guatemalans. Journal of Asthma, 39, 119-134.

Partridge, M. R. (2000). In what way may race, ethnicity or culture influence asthma outcomes? Thorax, $55,175-176$.

Strunk, R. C., Ford, J. G., \& Taggart, V. (2002). Reducing disparities in asthma care: Priorities for research - National Heart, Lung, and Blood Institute workshop report. Journal of Allergy \& Clinical Immunology, 109, 229-237.

Van Ganse, E., Leufkens, H. G., Vincken, W., Hubloue, I., Bartsch, P., Bouckaert, A., \& Ernst, P. (1997). Assessing asthma management from interviews of patients and family physicians. Journal of Asthma, 34, 203-209.

\title{
Acknowledgements
}

The authors wish to acknowledge the support and assistance of James A. Ellis, M.D., allergy/asthma consultant; Imperial County Public Health Department; Imperial County Child Asthma Project (0-5); California Asthma Among the School Aged Project (CAASA); and CMSP Wellness and Prevention (Adult Asthma Project).

\author{
Author Information \\ Paula Kriner, MPH* \\ Yolanda Bernal, BA \\ Amy Binggeli, MPH, RD, CHES \\ Imperial County Public Health Department, \\ 935 Broadway \\ El Centro, CA 92243 \\ India Ornelas, MPH \\ California Office of Binational Border Health \\ San Diego, California \\ * Corresponding author
}

